\title{
Cultural Factors that Influence M-Learning for Female University Students: A Saudi Arabian Case Study
}

\author{
Alaa Badwelan \\ Information \& Communication \\ Technology School, Griffith University \\ Brisbane, Australia
}

\author{
Adel A. Bahaddad \\ Faculty of Computing and IT \\ King Abdulaziz University \\ Jeddah, Kingdom of Saudi Arabia
}

\begin{abstract}
Mobile learning (m-learning) is one of the most technological environments used in higher education distance learning programmes. M-learning provides students with widespread access to classroom resources via mobile devices' networks and the possibility to learn regardless of their time and place. Many studies have shown the importance of the relationship between electronic systems and communities' traditions, because their increasing levels of acceptance depend on many moderators that directly affect the acceptance of M-learning communities. This study aims to verify the influence of demographic moderators in the UTAUT model to increase the level of learning perspectives acceptance via mobile in specific higher education communities and institutions. In the present study, the specific community is Saudi Arabia (KSA). The gender separation found in all stages of the Saudi education system is based on religious policies rooted in an Islamic perspective. Using m-learning smartphone applications could be helpful, yet also affected by traditional factors, in supporting women's efforts in higher education institutions in conservative countries such as KSA. The experiences that we uncover in KSA could be applied in other communities. The method used in the study is a quantitative approach based on a questionnaire completed by roughly 400 university students who are studying, at least in part, via their colleges' and universities' m-learning systems. The main objective of the study is to lead to a gradual increase in the number of remote learning students in many Saudi universities over the next five years according to Saudi vision 2030. With the conservative policies pursued in KSA in mind, women face a significant challenge in completing various education paths; thus, providing m-learning through electronic channels, such as mobile applications, could assist them significantly as they face these challenges.
\end{abstract}

\section{Keywords}

M-learning, Distance Learning Approach, Saudi Arabia, Questionnaire Survey, UTAUT

\section{INTRODUCTION}

Mobile learning (M-learning) represents one of the most important distance learning environments in higher education institutions. In the present decade, heavy investments have been made into M-learning to develop the necessary infrastructure and approaches to enable learning via smartphones. Furthermore, M-learning analyses and application designs have been widely popularised.

As emphasised in many previous studies, there are numerous advantages to using M-learning. It is easier to reach target audiences, and it enables students to learn at flexible times and in flexible places. However, there are still many obstacles that dramatically affect the advancement of M-learning. One significant obstacle is the inability of some communities to accept technology-based educational systems because of their cultures and traditions. Levels of M-learning acceptance often vary depending on the cultural milieu of a population. This study aims to verify the effect of cultural moderators on Mlearning by using a UTAUT model. The purpose of this analysis is to ultimately increase the level of acceptance of Mlearning in higher education institutions in Saudi Arabian society. This acceptance is especially for women students by gender for all levels of learning.

One of primary advantages of studying cultural moderators in M-learning is that it may eventually help to support female learning in KSA. The M-learning approach can be used in areas that do not have access to higher education or in regions that are seeking to maintain their culture, such as through the separation of genders in education for religious reasons. Mlearning could provide appropriate, consistent learning environments for communities with such cultural norms.

The target population in this study is university students in KSA who are interested in studying using an M-learning system. Students can take advantage of M-learning to explore the direct benefits and advantages of M-learning in higher education (e.g. obtaining a Bachelor degree, Master's degree, or Doctoral degree). Additionally, M-learning can be used to keep up with the demands of academic learning in many of Saudi universities. Given the conservative policies applied by the Saudi Arabian government, women face significant obstacles when pursuing an education. By providing the option of M-learning, female Saudi Arabian students are given a great opportunity to overcome challenges and access higher learning.

\section{LITERATURE REVIEW}

Researchers have covered many important M-learning topics in previous studies. It is important to consider these topics so that any potential gaps in the present study may be identified. The following literature review focuses on the basic definition of M-learning, the importance of M-learning, the importance of M-learning in higher education, and the importance of Mlearning in KSA. Previous studies that have applied theoretical acceptance models, such as Technology Acceptance Model (TAM), UTAUT, and the Learning Management System (LMS), are considered here.

\subsection{Definitions of M-Learning}

M-learning has become increasingly popular over the past decade. It focuses on using various modern ways of learning using smartphone technology [1]. M-learning can be defined as learning using either mobile phone devices like smartphones or other mobile devices like laptop computers [2]. For the purposes of this study, ultra-computers are excluded. Instead, this study focuses on devices that connect to the Internet via $3 \mathrm{G}$ or $4 \mathrm{G}$ wireless networks. The wireless network is a hallmark feature of smart devices, as it enables 
these devices to connect to the Internet and play multimedia files [3]. Another characteristic feature of M-learning is the ability to learn anywhere in the world and at any time of the day using a smartphone. A variety of educational opportunities can be offered by using smartphone technology, and these technologies are continuing to develop ([4],[5]). This flexibility encourages students to exchange educational resources using their smart devices without facing age or gender restrictions [1]. In summation, M-learning may be defined as an educational system that uses mobile devices to provide technology-based learning options to students.

\subsection{The M-Learning importance}

There are several aspects should be covered in the importance of M-Learning. These aspects are M-learning important in general, the M-learning importance in higher education, and M-learning importance for the academic institutes in KSA.

\subsubsection{The Importance of M-Learning}

Improvements in emerging smartphone technology have been one of the most fundamental reasons behind the increasing importance of M-learning in the present decade. These improvements have reduced the cost of smartphones as compared to PCs, which resulted in an increased number of smartphones being sold worldwide [6]. M-learning offers several enriching technology-based educational contexts, such as virtual classrooms, educational YouTube channels, and experimental methods that use blogs and flowchart to exchange knowledge ([6],[7],[8],[9]).

\subsubsection{Smartphones in KSA}

According to the fourth quarter report of the Ministry of Commerce concerning sales of electronic products in KSA in 2010 , mobile phone sales accounted for about $22 \%$ of KSA's spending on electronic products, with an expected growth rate of about $7 \%$ per year and an average spend of $\$ 1.1$ billion by 2015 [10]. The same study also reported a particular growth in demand for PDAs and $3 \mathrm{G}$ and $4 \mathrm{G}$ smartphones. In addition, it was estimated that in 2013 at least $71.3 \%$ of the Saudi population had access to the Internet via mobile phone [11]. As result, smartphone use in Saudi society is the third-highest level globally per head of population. There is an important opportunity to benefit from this trend by supporting $\mathrm{M}$ learning approaches to provide educational programs compatible with the aspirations of Saudi communities. Given the capabilities of M-learning, much of the potential of smart mobile devices remains untapped because of the relatively low level of technology awareness and expertise, as well as of users' acceptance and use of M-Learning technology [10]. Another study indicates that $3 \mathrm{G}$ users have increased in number to more than $38 \%$ of the mobile subscriber base [12]. These devices provide more cloud storage space, high-speed data processing and longer battery life. Featuring a range of graphical interfaces and supporting various file formats, these devices can help to target learners easily and conveniently.

\subsubsection{The Importance of M-Learning in Higher Education}

M-learning is based on modern technology like the Internet and smartphones, which have been decreasing in price [13]. Many features of M-learning have had significant impacts on learning in higher education. These features can be summarised into three major points. First, there is the possibility of quickly and easily exchanging knowledge among mobile learners because learning through M-learning applications does not require a special set of skills. Second, electronic materials are much lighter than traditional books and manuals which let the student see and carry their resources without any difficulties. Third, using an electronic pen to write offers more flexibility than a keyboard and mouse [14].

Previous studies indicate that other smartphone features also support M-learning approaches, such as the ability to access information online and to record and organise notes using smartphone applications. Furthermore, students can send and receive emails, photos, videos, SMS messages, and voice and video calls using social media applications ([9],[15],[16]).

The widespread use of mobile devices on campus invites more integrated educational methods related to M-learning, offering much greater availability and flexibility for students [17]. The use of PDAs, tablets, and smart phones in this context makes higher education more attractive to potential students for several reasons:

- These devices are cheaper than regular computers [15].

- These devices are useful and affordable [15].

- These devices have become more acceptable because they are easy to use [16].

- These devices can help to increase future M-learning benefits through features designed and built with a view to future technological development [18].

- These devices make M-learning a cooperative environment through opportunities to access study materials, including formative means assessment and feedback between students, and between student and teacher ([16],[19]).

In summary, the tablets and smart phones devices became more convenient for higher education student because of to provide many of fundamental requirements to deal with these devices in the universities. This will be helpful to use these facilities to improve the universities online learning environment to assist the student in this stage.

\subsubsection{The Importance of M-Learning in Higher Education in KSA}

Several researchers have suggested that technology has had a positive impact on the learning process. Therefore, many higher education institutions have invested in technology to improve their learning tools, develop students' skills, and enable students to access information online.

Many researchers have used M-learning to measure specific factors that influence e-learning acceptance among students and teachers ([20],[21],[22],[23]) An acceptance level towards technology in education varies from one community to another within developed countries and represents an important emerging issue. This variation confirms that the specifications and characteristics of M-learning do differ from one country to another ([15],[16]). Therefore, identifying unique M-learning characteristics from country to country is important for measuring the acceptance of M-learning within target populations. Approaches to distance learning are also different in universities that formerly participate in distance education. In distance education, students can download course materials through university webpages, and teachers can communicate with students through SMS [24]. 


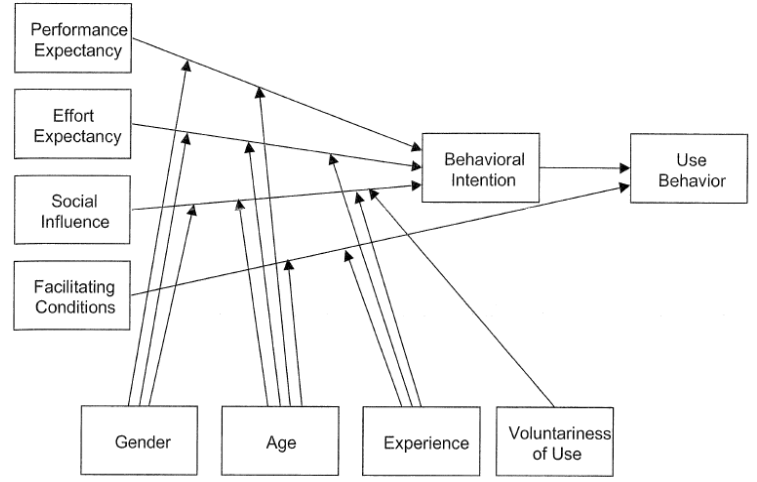

Figure 1: The UTAUT Model (Venkatesh et al, 2003)

The importance of M-learning in KSA has increased in the current decade due to rapid advances in wireless networks and mobile phone technology. Smartphone users now make up $73 \%$ of the Saudi population, and two thirds of Internet subscribers use 3G networks to access the Internet ([11],[12]). Some universities are investing their funds to enhance and expand the M-learning field. These measures have been taken in response to the Saudi government's vision (2030) of introducing transformative investments that move beyond a framework of oil and into a knowledge-based economy ([10],[25]). Participating universities include King Abdul Aziz University, King Faisal University, Imam Muhammad bin Saud Islamic University, and Saudi Electronic University. As well, "Afaq project" has been adopted and implemented by the Ministry of Education by creating infrastructure to meet online education requirements in all universities. This infrastructure includes the National Centre for E-Learning and Distance Education (NCELDE), and LMS ([10],[26]). The main objective behind creating this infrastructure is to stimulate the growth of distance learning via mobile phones. Overall, the project aims to meet the growing demands of expected M-learning audiences and to provide useful Mlearning features like enhanced speed and flexibility [10].

\subsection{General studies on m-learning acceptance}

Studies in the M-learning field represent part of a trend toward accepting technical frameworks in education and better understanding their influence on M-learning factors, such as studies that focus on TAM and UTAUT theoretical frameworks. According to a study by [15], the TAM framework focuses on determining the effects of external variables that influence to increase the acceptance level in Mlearning approach, such as determine the educational systems factors and their impact on users' satisfaction, users' attitudes towards users' behavioural intentions (BI) [15]. The TAM framework includes two main constructs: perceived usefulness (PU) and perceived ease of use (PEOU). The PU and PEOU are used to study levels of technological acceptance and to determine the value added with the M-learning approach. These aspects are also included in the UTAUT model, which is another version of the TAM model. There are many other theoretical frameworks, such as the innovation Of Diffusion (DOI) model, the Theory of Reasoned Action (TRA) model, the Motivation Model (MM), and the Social Cognitive Theory (SCT) model. The UTAUT model includes four main constructs: performance expectancy (PE), effort expectancy (EE), facilitating conditions (FC), and social influence (SI) (see figure 1). Also, the UTAUT model includes numerous cultural moderators, including age, gender, experience, and
Voluntariness of Use that is used to interpret the different degrees of acceptance among electronic users' systems ([16],[27]). It is necessary to identify M-learning trends from previous studies to better study the technological, psychological, and social characteristics of M-learning, as these are elements to help build the constructs of UTAUT.

In [15] study, the researchers focused on verifying factors that influence M-learning acceptance among students. Their model included personal innovativeness (PInn), the social influence of lecturers (LI), PE, and EE, which are the main constructs of the UTAUT model in this study. The purpose of this study was to examine the effects of social and psychological variables on expected M-learning acceptance in a target audience [15]. The results indicated that the constructs of the model did influence the undergraduate students' relationships toward M-learning. Additionally, the study indicated that the effort expectancy represents one of the largest sources of the intention to use university-level students [15]. [22] focused on the acceptance of M-learning. [22] developed the UTAUT model, which includes self-efficacy, attainment value, perceived enjoyment, and self-management. These constructs are used to study the level of technical efficiency present in distance learning. The UTAUT model of this study is developed based on the current constructs. The results show that there are deficiencies in the social influence of participants, thereby revealing a limitation of the study. Another study conducted by Ju's study (2007) demonstrates that PEOU is derived from the TAM model and has a positive impact on M-learning (Ju et al., 2007). Thus, this study has confirmed the importance of PU in IT support and M-learning.

Iqbal and Qureshi (2012) developed an integrated framework that combined TAM and UTAUT by adding PU and PEOU to their proposed theoretical framework. The purpose of their model was to measure levels of self-motivation using technology-based educational systems among participants towards M-learning field. The results indicated that PU had no significant impact on users' attitudes towards adopting an Mlearning approach (Iqbal \& Qureshi, 2012). It might be the number of participants was little which is caused the insignificant results between PU and BI and few study participants who owned smartphones. The study results also illustrated the potential negative impacts of SI when adopting M-learning. This can be attributed to the low impact of the SI construct on developing the technical aspects of M-learning [29]. Relevant statistical relationships were identified between M-learning adoption and all other constructs in the UTAUT model in previous studies (e.g.[15],[22],[28],[29]). Therefore, the inclusions of a variety of standards to support the acceptance of M-learning, such as motivational, psychological, and social standards, were shown to lead to significant improvements in the UTAUT model. It represents the difference between traditional Learning and M-learning services.

Some basic assumptions of the UTAUT framework are problematised in [30]. In particular, the findings of this study suggest that only performance expectancy and effort expectancy have any significant effect on behavioural intention to use M-learning technology. In contrast, selfmanagement, age and gender as mediating factors have no substantial significance for M-learning adoption among learners.

In a related study, [31] tested M-learning technology acceptance among 390 students in Thai public and private universities. While the authors utilized exactly the same factors (performance expectancy, effort expectancy, 
facilitating conditions, and social factors) as in the classic UTAUT framework, they embedded them in a slightly modified explanatory framework. In particular, the researchers omitted moderating factors, including age and gender, and instead used Attitude Towards Behaviour (AT) and Behavioural Intention (BI) as two basic variables produced by the constellation of four factors and directly affecting the final decision of users to adopt M-learning (2009, p. 3). The basic hypothesis developed by [31] is that "attitude towards behaviour (AT) has a significant positive relationship with behaviour intention to use (BI)" ([31], p. 3). Here, the authors have introduced a crucial intermediary link between students' perceptions of M-learning and propensity to adopt.

Finally, [9] study is important in bridging a gap in the analysis of gender and age as factors in M-learning technology acceptance. In particular, it was demonstrated that age differences moderate the impact of social influence and effort expectancy on M-learning use intention [9]. That is, for older mobile learners, high effort expectancy and social influence may play a greater role in M-learning adoption. Additionally, it was established that gender differences moderate the impact of self-management on learning and of social influence on Mlearning acceptance. In particular, the study demonstrated that social influence is "...a stronger predictor behavioural intention for men than for women" and "...self-management of learning influenced behavioural intention more strongly for women than for men" [9]. The authors hypothesized that the lesser impact of social influence on women may possibly be explained by “....women being more unfamiliar with relatively advanced and complex M-learning technology, making them less likely to be influenced by their close friends in the early stages of M-learning development" [9]. Although this hypothesis seems plausible, one must take the cultural and national context of M-learning adoption into account, as the study was conducted among Taiwanese students (330 respondents), who may differ from their Western peers.

A number of studies have addressed the factors influencing students' acceptance of M-learning. There are number of studies that applied UTAUT to explore M-learning acceptance, which indicate that student acceptance of the Mlearning approach is central in designing a successful $\mathrm{M}$ learning system. These factors must be more fully investigated if we are to overcome all the challenges and difficulties of Mlearning acceptance.

Previous studies have sought to understand M-Learning among students and the adoption of M-learning in general. Having reviewed these studies, the proposed theoretical framework of this study consists of the constructs of both UTAUT and TAM. This framework will facilitate the study of factors that influence students' acceptance of M-learning in higher education institutions in KSA. This study also focuses on measuring levels of student interest towards M-learning and activating various variables, like perceived playfulness and attainment. This approach will help to measure the psychological and social aspects of the target population in this study.

\subsection{M-Learning Acceptance in KSA}

Several attempts have been made to apply the UTAUT model to the analysis of M-learning use intention among Saudi Arabian students. In particular, [16] surveyed 80 students from Saudi private universities to determine the relative weights of various UTAUT factors in M-learning acceptance. The study established a significant correlation between the factors of the UTAUT model and M-learning adoption.
However, the validity of these findings may be limited in a number of ways. In particular, the study sample was not sufficient to satisfy generalization criteria (only 80 respondents from 100 to whom questionnaires were distributed took part in the research). Secondly, the research sample was selected from the private Al-Faisal University, which is not representative of Saudi higher education in general. In fact, public universities account for more than $90 \%$ of higher degree students in KSA and make the largest contribution to online learning facilities and courses (e.g. King Abdulaziz University, Al Imam Muhammad Ibn Saud Islamic University).

Some Saudi Arabian universities have made progress in providing the requirements necessary for the integration of distance learning into the educational system and to improve the educational environment. [32] conducted a study that aimed to improve the quality of e-learning; it was carried out at King Fahd University of Petroleum and Minerals (KFUPM). The study was an initiative that tested the acceptance of technology-based educational systems at the university, such as the Tajsir initiative in e-learning to manage e-learning. This initiative was largely accepted by the target audience [32]. This study was also similar to other studies that addressed the M-learning context in KSA, and it was conducted in 2011 by [33]. It focused on identifying participants' perceptions about the efficiency of M-learning and its impact on the teaching process and student learning. The study also mentioned some restrictions regarding smartphone devices, such as memory size, battery life, improved Internet connectivity, user interfaces for differing operating systems (OS), and network coverage for mobile phone services in KSA [33]. Furthermore, the study demonstrated the importance of certain factors that can help researchers to evaluate the advantages and disadvantages of the M-learning field for students. Among the disadvantages are small screen sizes and the incompatibility between the OS of smart devices and M-learning applications [33].

Similarly, [34] noted the need to take account of the technical limitations of M-learning when building such systems and/or models. In particular, they argued that the smaller screen sizes of mobile devices require content optimization and connectivity risk prevention based on a system that updates the content of disconnected devices [34]. Other possible limitations of M-learning addressed by these researchers include distraction among mobile learners, fragmented experiences, additional costs and security risks [34]. [32] also considered in detail the present limitations of e-learning implementation in KSA, on the basis that many students in KSA “...do not have reliable and cheap Internet access from home, and because campus IT security makes it difficult for students off campus to access the servers on campus" (2013, p. 79). Another recurring problem is that the educational management of KSA universities frequently hesitate to introduce full M-learning and e-learning courses owing to administrative, social and security concerns.

Utilising feedback from M-learning users has been an important tool in developing M-learning in KSA, as demonstrated by [34] in their research. The feedback of Mlearning users system was adopted to provide customers with access to educational content via software and to communicate with other educational applications, thus enabling researchers to identify participants' views about Mlearning systems in general [34]. However, The M-learning applications that include a technical approach should be reevaluation, as they operate along the same line as current 
developments in web technology. This technical approach can be developed or replaced, depending on the demands of the target populations in the M-learning field instead using the same framework of e-Learning web technology in the Mlearning applications.

[35] Attempted to develop an adaptive mobile learning framework integrating a range of personalized learning techniques to meet the differing learning needs of students. The authors produced a design for a prototype tool, labelled Adaptive Mobile Learning System (AMLS), which was tested on 128 participating students. This adaptive mobile learning framework as promoted by [35] is a promising development in the field of M-learning, facilitating personalization of course delivery, learning materials, interaction styles, techniques and assignments, based on analysis of e-profiles of students that typically involves machine learning algorithms and/or questionnaires. Such personalization facilitates a transition from instructor-centred curricula to learner-centred approaches as celebrated by [32] among others.

The AMLS system developed by [35] involves two agents: a Filtering Agent and a Pedagogical Agent. The former program filters and analyses learning styles and preferences by means of questionnaires and long-term assessment of students' web requests for image, audio and textual materials. Based on this data, the Pedagogical Agent then assigns and distributes various learning objects compatible with students' learning trajectories [35]. The survey, administered among distance learners at King Abdul-Aziz University, KSA, revealed a number of advantages of AMLS over traditional learning systems in terms of accessibility, usability and overall student satisfaction. However, among the main limitations of this study is the non-inclusion of any technology acceptance framework such as UTAUT or TAM, making it difficult to assess how the various parameters of the AMLS framework affect students' perceptions of adaptive mobile learning. Future research and development of mobile learning systems will benefit from the integration of such technology acceptance frameworks in assessing students' attitudes and customizing systems to improve usability and overall UX. In a follow-up study, [35] extended their initial framework to include new agents and parameters integrating social and adaptive agents. In particular, an effort was made to leverage the vast flow of students' social network data to improve the adaptivity of mobile-based courses. Social agents (SA) created by [35] were able to tag materials and activities, make wiki entries and share knowledge and learning experiences through Facebook, substantially improving the collaborative knowledge environment for mobile learning courses.

As mentioned previously, several studies have already sought to assess the impact of technology and its acceptance within diverse populations of Saudi Arabian society. There are significant issues to consider, such as gender segregation within education. Therefore, re-examining students' levels of acceptance of M-learning in educational institutions in KSA from the perspective of gender could be beneficial and positively affect Saudi Arabian society. Previous studies have focused on increasing the confidence levels of the target audience; this approach has significantly increased the audiences' acceptance levels. Therefore, additional research is required to study factors that affect performance and level of user intentions, such as the research conducted by [5]. This study found that the positive perceptions of students towards M-learning led to increased rates of learning through mobile devices. The study demonstrated that acceptance does depend on previous M-learning experience and can be improved with additional stimulus. In this research, the sample size was insufficient for an academic study, as there were only 39 participants [5]. Additionally, the majority of the students' opinions about using M-learning technologies were neutral. In future research, it would therefore be necessary to conduct retesting using same content but with an increased number of participants.

\subsection{Framework of M-Learning in KSA}

The proposed theoretical framework for this study is based on previous studies. This study employs the UTAUT model to measure participants' acceptance of M-learning. It also seeks to provide an integrated model to measure the acceptance level of M-learning approach by reviewing various frameworks ideas ([15],[33]). The UTAUT model used in this study includes two main moderators. These are a fundamental element for identifying the characteristics of a target population, which is expected to be acceptable with Mlearning. These two moderators are gender and previous experience, both of which open avenues for exploration and enhanced understanding. These moderators will help to identify relevant factors that affect the acceptance of technology-based learning and individuals' intentions to regularly use those technologies. Therefore, it is important to adjust the UTAUT framework in each specific context in the M-learning acceptance model. The literature review led to some modifications being made to the UTAUT model. It focused on various constructs within the model, such as perceived playfulness, PInn, attainment value, quality of service, self-management of learning (SL), and self-efficacy. Based on the previous description, this study will focus on the following terms which are:

- Performance Expectancy-personal belief in whether an information technology can contribute to educational and professional performance and/or success

- Effort Expectancy - attitude towards effort (knowledge and time) required to master an information technology

- Lecturers' Influence - the extent to which a person believes in the importance of others' attitudes towards his/her usage of a given technology

- Personal Innovativeness - a measure of a person's creativity and willingness to try out any new information technology

- Self-Management of Learning - a person's evaluation of his/her own capacity for independent learning, educational self-discipline, self-organization and critical thinking

- Behavioural Intention-one's behavioural disposition towards use of an information technology as affected by the above factors

Based on the review of previous studies, this study focuses on three constructs that have been adopted from the original UTAUT model: EE, BI, and PE. Several additional modifications have been made. The SI construct has been changed to LI in M-learning. Additionally, SL and PInn in the field of education have been added because they are important for understanding the context of M-learning. Specifically, the PInn field refers to an individual's desire to have creative experiences using new information technology and to develop their personal creative abilities. Also, SL refers to the importance of developing self-discipline and time management, as these are required to independently deal with educational requirements, such as duties and assignment. Additionally, in this study, the model moderators are reduced to gender and experience, while age and willingness to participate were omitted from the study model. The age 
moderator was excluded because the model tests university students who belong to a similar age group and have similar ways of thinking. Willingness to participate was excluded because in dealing with M-learning, it is important to identify participants' levels of acceptance because the participants characteristics might be adopted in Saudi universities in the future. The other two moderators will each be divided into two main groups. Experience is divided into either "high," which represents more than three years of experience and "low," which represents three years of experience or less. Finally, gender is divided into male and female groups in this study.

\section{METHODOLOGY}

In this study, a questionnaire was used to gather data from the target population. Few UTAUT studies have been conducted concerning M-learning in Saudi Arabian universities. This means that it is especially important to determine how various factors affect acceptance levels within M-learning in KSA. Within this study, open-ended questions were included for participants who wished to add new factors. Participants' points of view were examined using a Likert Scale and participants were asked about the importance of certain factors. The main groups consisted of PE, EE, LI, Plnn, SL, and BI. Total of influential factors is 24 altogether. The survey was sent electronically using a mailing list, so that a large population could easily be reached. The length of the hyperlink was reduced using software from Google to facilitate the transmission of the questionnaire across multiple social media platforms ([36],[37]). It was added some processes to ensure understandable meaning that is needed for target segment. The survey was revised and arbitrated by three academics in the information System field. Each participant responded to the survey by answering three conditional questions. The first question concerned their previous experience with e-learning and smartphone systems, the second question asked whether they were an undergraduate or graduate student, and the third question asked whether they were a resident of KSA or just living in the country. The participants were provided with the objective of the study and the contact information of the research team so that they could ask questions [38]. There were a total of 401 completed responses. The sample size was calculated using two main variables that had a confidence level of $95 \%$ and a margin of acceptable error of $5 \%$.

\section{ANALYSIS}

In this study, the results of statistical testing were analysed to validate the model and its hypotheses. This included internal reliability, factor analysis, composite reliability, average variance extracted, exploratory factor analysis (EFA), confirmatory factor analysis (CFA), and structural equation modelling (SEM). Each of these is described in the section that follows.

\subsection{Results of the Demographic Questions}

The demographic questions address participants' characteristics, such as participant's ages, genders, and educational levels. Other questions focus on the target population and deal with the properties of M-learning. The fourth question in the survey specifically focuses on previous experience in the field of M-learning, whereby $51.1 \%$ of participants had five or more years of M-learning experience. The fifth question focuses on participants' knowledge of Mlearning, which revealed that $65 \%$ of respondents had average or above average levels of experience. The sixth question refers to the number of uses by the mobile devices for learning every day. The results indicate that $62.5 \%$ of participants used M-learning once or more a day, thereby indicating that university students are highly willing to accept and use Mlearning. The ninth question relates to participants' preferred types of OS. The results revealed that $37 \%$ of people use Apple iOS and $42.6 \%$ use Android OS. The eleventh question refers to the types of smart devices that are most preferred in M-learning. The top three are smartphones, tablets, and iPads at $29.7 \%, 12.7 \%$, and $21.4 \%$, respectively.

Table 1: Results of M-learning for the Measurement Model

\begin{tabular}{|c|c|c|c|c|c|c|c|}
\hline 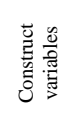 & 咅 & 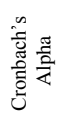 & 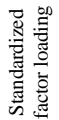 & 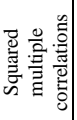 & 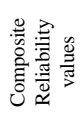 & $\frac{1}{4}$ & 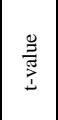 \\
\hline $\begin{array}{l}\text { PE1 } \\
\text { PE2 } \\
\text { PE3 } \\
\text { PE4 } \\
\text { PE5 }\end{array}$ & $\begin{array}{l}.779 \\
.773 \\
.803 \\
.729 \\
.812\end{array}$ & ฮ̆ & $\begin{array}{l}.836 \\
.859 \\
.851 \\
.719 \\
.877\end{array}$ & $\begin{array}{l}.700 \\
.738 \\
.724 \\
.517 \\
.768\end{array}$ & $\stackrel{\infty}{\stackrel{\infty}{\sigma}}$ & 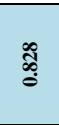 & $\begin{array}{l}\text { ڤે } \\
\text { ڤે }\end{array}$ \\
\hline $\begin{array}{l}\text { EE1 } \\
\text { EE2 } \\
\text { EE3 } \\
\text { EE4 }\end{array}$ & $\begin{array}{l}.661 \\
.868 \\
.877 \\
.766 \\
\end{array}$ & ڤેे & $\begin{array}{l}.716 \\
.857 \\
.873 \\
.749\end{array}$ & $\begin{array}{l}.512 \\
.734 \\
.762 \\
.561 \\
\end{array}$ & $\begin{array}{l}00 \\
\stackrel{0}{0}\end{array}$ & ફે & స్త్ర \\
\hline $\begin{array}{l}\text { LI1 } \\
\text { LI2 }\end{array}$ & $\begin{array}{l}.787 \\
.732\end{array}$ & 0.851 & $\begin{array}{l}.806 \\
.917\end{array}$ & $\begin{array}{l}.650 \\
.842\end{array}$ & 0.983 & 0.822 & 9.969 \\
\hline $\begin{array}{l}\text { PLNN } \\
\text { PLNN } \\
\text { PLNN }\end{array}$ & $\begin{array}{l}.774 \\
.764 \\
.738\end{array}$ & $0.79 ?$ & $\begin{array}{l}.785 \\
.808 \\
.676\end{array}$ & $\begin{array}{l}.617 \\
.653 \\
.457\end{array}$ & 0.979 & 0.756 & $\mid 7.069$ \\
\hline $\begin{array}{l}\text { SL1 } \\
\text { SL2 } \\
\text { SL3 } \\
\text { SL4 } \\
\end{array}$ & $\begin{array}{l}.512 \\
.829 \\
.812 \\
.820\end{array}$ & $\stackrel{5}{\overrightarrow{0}}$ & $\begin{array}{l}.496 \\
.733 \\
.857 \\
.821 \\
\end{array}$ & $\begin{array}{l}.466 \\
.537 \\
.734 \\
.674 \\
\end{array}$ & हू & $\stackrel{\hat{A}}{\stackrel{s}{S}}$ & ஜ̊̊ \\
\hline $\begin{array}{l}\text { BI1 } \\
\text { BI2 } \\
\text { BI3 } \\
\text { BI4 } \\
\text { BI5 } \\
\end{array}$ & $\begin{array}{l}.663 \\
.716 \\
.725 \\
.772 \\
.750 \\
\end{array}$ & ఫ. & $\begin{array}{l}.850 \\
.860 \\
.899 \\
.861 \\
.893 \\
\end{array}$ & $\begin{array}{l}.722 \\
.740 \\
.808 \\
.742 \\
.798 \\
\end{array}$ & 今े & 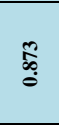 & $\stackrel{\bar{g}}{=}$ \\
\hline
\end{tabular}

\subsection{Measurement Model Results}

The table 1 indicates that the Factor extracted values in the Constructs were recorded higher than 0.5 and the value of the AVE was higher than 0.5. The AVE values were ranging between 0.873 and .0 .727 and the CR values ranged between 0.971 and 0.987 . The highest value of Squared multiple correlations was 0.842 while the smallest value was 0.457 . Thus, these indicators are pointing to the differentiation in the used scales, and that should be enough in the M-Learning model. Even though the values in Squared multiple correlations should be 0.5 or more, but the PLNN3 and SL1 recorded less than 0.5 which were 0.457 and 0.466 respectively. These two values have been accepted because the CR and AVE values were higher than the proposed model values and other factors in the same constructs can load the shortage of these values. Moreover, the Factor loading values were between 0.621 and 0.834 . Also, all of them were significant at $p<0.001$. No factors has been excluded in this stage of analysis, because the accepted values and compatible among the factors. The final result of this part indicates the convergence between the values in the tests, which lead to the reliability of the variables in the model constructs.

One measuring aspect that is used to measure the discriminant validity between the factors is compared the square root of the AVE values with each Constructs in the Model [39]. If the square roots of AVE values are bigger than other constructs values, which means each Constructs are closely linked other Constructs [39]. As shown in Table 1, the squared root of AVEs is larger than the correlation of each constructs. The numbers with dark blue represents the square root of the AVEs at level of 0.001 . See the table 2

After that, the relationships between the constructs were calculated by three main indicators which are t-value, $\mathrm{p}$-value, and Standardized regression coefficient. The Constructs result 
was shown proportionate and significant for all model hypotheses from $\mathrm{H} 1$ to $\mathrm{H} 5$. The value of Standardized regression coefficient were between 0.749 and 0.533 and the p-value was significant in the level 0.001 and the $\mathrm{R} 2$ values between 10.905 and .7 .069 which is recommended more than 1.96 ranged. As shown in the table 1 all the modelling fit indicators in the acceptable level as presented in the path coefficient structure model

The result of previous statistical tests shows all the model constructs (Performance expectancy, Effort expectancy, Lecturers' influence, Personal innovativeness, and Self- management of learning) have positive effects on behavioural intention to use M-learning. As mentioned in the table 2.

\begin{tabular}{|c|c|c|c|c|c|c|c|}
\hline$\overline{\mathbf{P E}}$ & $\overline{\mathbf{E E}}$ & LI & PInn & $\overline{S L}$ & BI & Mean & SD \\
\hline 0.686 & & & & & & 4.142 & 0.915 \\
\hline .503 & 0.638 & & & & & 4.630 & 0.613 \\
\hline .460 & .407 & 0.675 & & & & 4.126 & 0.923 \\
\hline .500 & .346 & .521 & 0.672 & & & 4.182 & 0.839 \\
\hline .334 & .230 & .453 & .570 & 0.528 & & 4.093 & 0.873 \\
\hline .549 & .533 & .606 & .655 & .531 & 0.761 & 4.139 & 0.981 \\
\hline
\end{tabular}

Figure 2: the M-Learning Model with the Hypotheses

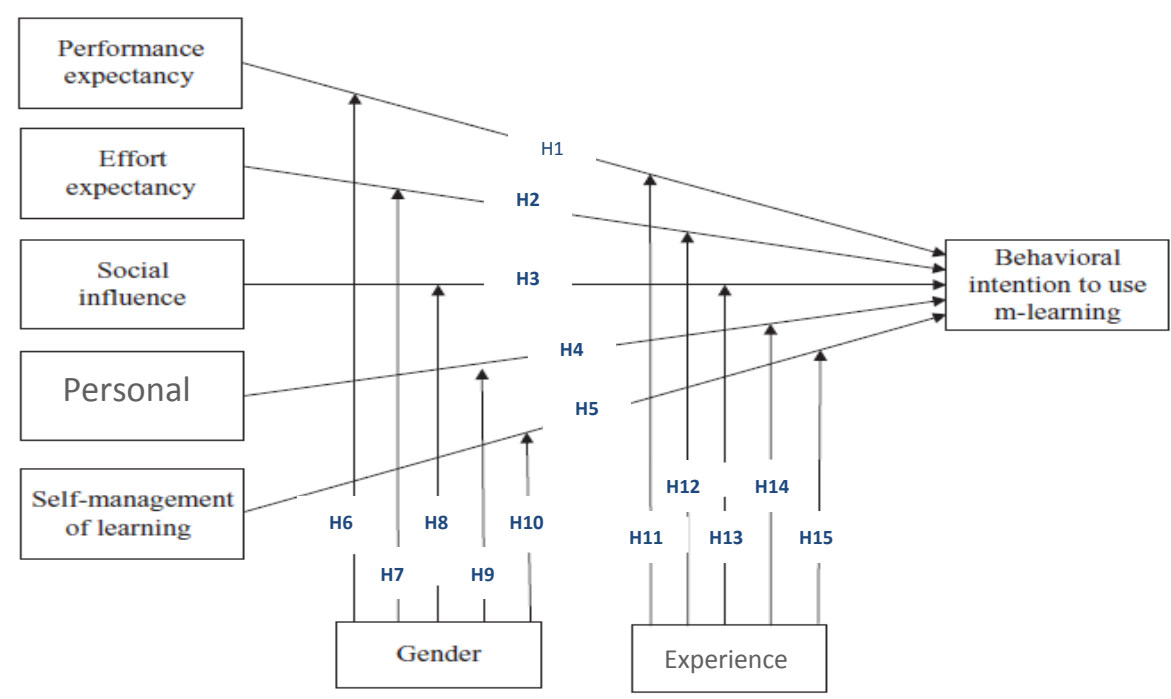

\subsection{The Moderators Hypothesis test}

In various of previous studies which were conducted on many theoretical models such as UTAUT, TAM to determine and adopt technology framework, behaviour moderators are represent one of the fundamental aspects to dealing with the technical acceptance and proliferation in general [27]. Therefore, it was founded many of these moderators which have been tested in many previous researches which were shown a good acceptance of this approach in a different study samples. For Examples of these moderators, the gender and experience which are influenced by cultural society. These moderators are impact to accept new technologies and adopt in different societies. Therefore, according to a study [15] the technological acceptance depend on the moderators represent an important approach to deal with the theoretical models depending on the unique characteristics of specific communities. In this part of analysis, it was study the acceptance level of M-learning in the higher education students in Saudi universities across two moderators which are the Gender and level of experience. Each of these moderators has been divided into two groups. The gender moderators as separated into male and female group. The experience moderators has been separated into high level of experience which is more than 3 years' experience and the low level of experience which is three years' experience and less. The number of these moderators groups were equal as presented in the Table 3.

The goal to use these moderators is discovering the differences between the participants groups in this study and determines the level of acceptance in M-Learning in UTAUT model. As well as, the Correlation Coefficients, Critical ratio, and P-Value are calculated per each Constructs to determine the significant relationships between variables in the Constructs.

Table 3: The Number of Research Moderators by Group

\begin{tabular}{|lccc|}
\hline \multirow{2}{*}{ Moderator Name } & Group & \multicolumn{2}{c|}{$\begin{array}{c}\text { The sample distributed by } \\
\text { moderator groups }\end{array}$} \\
& Level & N & P \\
\hline \multirow{2}{*}{ Gender } & Male & 194 & $48.4 \%$ \\
& Female & 207 & $\mathbf{5 1 . 6 \%}$ \\
\hline \multirow{2}{*}{ Experience } & High & $\mathbf{1 9 6}$ & $\mathbf{4 8 . 9 \%}$ \\
& Low & $\mathbf{2 0 5}$ & $\mathbf{5 1 . 1 \%}$ \\
\hline
\end{tabular}

It has been calculate the differences in the results between moderators group in the study sample. The males sample was represented about $48.4 \%$, while the females group represent $51.6 \%$ as shown in Table 4, and the coefficients study PE $\rightarrow$ $\mathrm{BI}-\mathrm{EE} \rightarrow \mathrm{BI}-\mathrm{LI} \rightarrow \mathrm{BI}-\mathrm{Plnn} \rightarrow \mathrm{BI}-\mathrm{SL} \rightarrow \mathrm{BI}$ have significant result in the male and female groups. This is meaning the gender moderator in this study has significantly interested to accept the M-learning in higher education institutions in KSA. Moreover, the expertise moderator represent one of important moderator because of the people accepts to use and learning the technology that they are familiar and close with it. Therefore, the experience aspect to dealing with smart devices represents fundamental moderator in this area. As shown in the table 4 and 15 all previous study paths in the

Gender and level of experience are significant values for the sample study. 
Table 4: Summary of Testing Results for the Path Coefficients, $t$-values, and P-values of Moderator Hypotheses

\begin{tabular}{|c|c|c|c|c|c|c|c|}
\hline \multirow{2}{*}{\multicolumn{2}{|c|}{ Gender }} & \multicolumn{2}{|c|}{$\begin{array}{c}\text { Male, } \mathrm{N}=194 \\
48.4 \%\end{array}$} & \multicolumn{3}{|c|}{ Female, $N=207,51.6 \%$} & \multirow[t]{2}{*}{ Testing Result } \\
\hline & & Estimat & \begin{tabular}{|l|l}
-value & $P$ \\
\end{tabular} & Estimate & t-value & $\mathrm{P}$ & \\
\hline H1 & $\mathrm{PE} \rightarrow \mathrm{BI}$ & .692 & $6.853^{* * * *}$ & .357 & 4.231 & **** & Supported \\
\hline $\mathrm{H} 2$ & $\mathrm{EE} \rightarrow \mathrm{BI}$ & .684 & $7.233^{\text {**** }}$ & .822 & 7.718 & **** & Supported \\
\hline H3 & $\mathrm{LI} \rightarrow \mathrm{BI}$ & .551 & 5.514 k** & .513 & 5.708 & $* * *$ & Supported \\
\hline H4 & PInn $\rightarrow$ BI & .534 & 6.361 k*** & .635 & 6.769 & **** & Supported \\
\hline H5 & $\mathrm{SL} \rightarrow \mathrm{BI}$ & .680 & 5.740 *** & .645 & 6.197 & $* * *$ & Supported \\
\hline \multirow{2}{*}{\multicolumn{2}{|c|}{ Experience }} & \multicolumn{2}{|c|}{$\begin{array}{l}\text { High - more than } \\
\text { four years, } \\
\mathrm{N}=196,48.9 \%\end{array}$} & \multicolumn{3}{|c|}{$\begin{array}{c}\text { Low }- \text { Less than } \\
\text { four years, } \mathrm{N}=205, \\
51.1 \%\end{array}$} & \multirow[t]{2}{*}{ Testing Result } \\
\hline & & Estimat & \begin{tabular}{l|l|}
-value & P \\
\end{tabular} & Estimate & t-value & $\mathrm{P}$ & \\
\hline H6 & $\mathrm{PE} \rightarrow \mathrm{BI}$ & .461 & 5.106 k** & .608 & 6.482 & *** & Supported \\
\hline $\mathrm{H} 7$ & $\mathrm{EE} \rightarrow \mathrm{BI}$ & .819 & 7.680 k** & .670 & 7.205 & **** & Supported \\
\hline H8 & $\mathrm{LI} \rightarrow \mathrm{BI}$ & .451 & 4.847 k** & .597 & 6.260 & $* * *$ & Supported \\
\hline H9 & Plnn $\rightarrow$ BI & .668 & $6.758^{* * * *}$ & .544 & \begin{tabular}{|l|}
6.224 \\
\end{tabular} & **** & Supported \\
\hline $\mathrm{H} 10$ & $\mathrm{SL} \rightarrow \mathrm{BI}$ & .683 & 6.260 *** & .608 & 5.434 & **** & Supported \\
\hline \multicolumn{8}{|c|}{$\begin{array}{c}\text { PE = Performance Expectancy, EE = Effort Expectancy, } \\
\text { LI = Lecturers' Influence, PInn = Personal Innovativeness, } \\
\text { SL = Self-management of learning, BI = Behavioural Intention, } \\
* p<0.1 ; * * p<0.05 ; * * p<0.001\end{array}$} \\
\hline
\end{tabular}

\subsection{Testing the Nomological Validity of M-learning acceptance requirement Measurement Model}

One of the most powerful means to check the validity of Measurement Model is Nomological [40]. Therefore, the validity of Nomological refers to the degree of correlation values in the statistical tables with similar conceptually procedure through the evaluation of the best method to ensure the theoretical model validity [41]. As well as the Nomological validity reflect the amount of predictions about the influence factors in the original model [42]. In this study, it was assessed the Nomological validity through construct the SEM for the acceptance factors M-Learning in higher education institutions in KSA by using the appropriate Goodness-of-Fit indicators. The SEM approach is adopted because the purpose of this study testing the convergence power of, differentiation, and the Nomological validity in the influence factors to accept M-Learning in this research. Therefore, the validity of the standard of Model theoretical will be helpful to measure the fundamental factors to accept a M-learning model in higher education students in Saudi Arabian Universities.

This study was designed to develop and test the Nomological validity, which includes test relations between the constructs and the factors influencing the acceptance of M-Learning in higher education students in Saudi universities. The hypotheses in this study distributed into two groups: the first group of hypotheses is focus to test theoretical model and test the acceptance of the associated constructs in the model. These assumptions and hypotheses are numbered from H1 H5. The second group which focuses on Moderators assumptions was divided into two main moderators which are Gender and Experience. The sample is separated according to the specific statistical considerations, which shown significant relationship in each part of the study, which have been addressed extensively earlier in this chapter.

Form influencing factors to accept the M-Learning in higher education institutions in KSA, as shown in Figure 6 as Nomological network to identify validity of Constructs that reflect the basic requirements of the Model acceptance. These aspects determine the relationships among the factors influencing the acceptance of the theoretical approach. The
Correlation analysis was conducted in the table 5 and the results indicate that all the factors in the constructs have significant relationships. These relationship produces the analyses concluded that the current study gives a complete visualization to identify the key factors for M-learning in higher education institutions in KSA also has Nomological validity.

Table 5: Summary of moderator hypothesis testing result

\begin{tabular}{|c|c|c|}
\hline 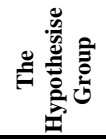 & ن & The Hypothesis \\
\hline \multirow{5}{*}{ 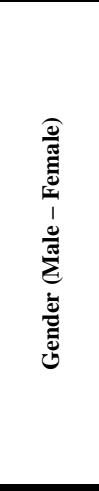 } & H1 & $\begin{array}{l}\text { Performance expectancy influences } \\
\text { behavioural intention to use M-learning more } \\
\text { positively for male than for female users of } \\
\text { mobile devices. }\end{array}$ \\
\hline & H2 & $\begin{array}{l}\text { Effort expectancy influences behavioural } \\
\text { intention to use M-learning more positively for } \\
\text { male than for female users of mobile devices. }\end{array}$ \\
\hline & $\mathbf{H 3}$ & $\begin{array}{l}\text { Lecturers influence behavioural intention to } \\
\text { use M-learning more positively for male than } \\
\text { for female users of mobile devices. }\end{array}$ \\
\hline & H4 & $\begin{array}{l}\text { Personal innovativeness influences behavioural } \\
\text { intention to use M-learning more positively for } \\
\text { male than for female users of mobile devices. }\end{array}$ \\
\hline & H5 & $\begin{array}{l}\text { Self-management of learning influences } \\
\text { behavioural intention to use M-learning more } \\
\text { positively for male than for female users of } \\
\text { mobile devices. }\end{array}$ \\
\hline \multirow{5}{*}{ 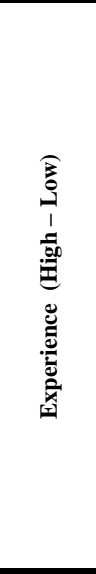 } & H6 & $\begin{array}{l}\text { Performance expectancy influences } \\
\text { behavioural intention to use M-learning more } \\
\text { positively for experienced users of mobile } \\
\text { devices than for less experienced users. }\end{array}$ \\
\hline & H7 & $\begin{array}{l}\text { Effort expectancy influences behavioural } \\
\text { intention to use M-learning more positively for } \\
\text { experienced users of mobile devices than for } \\
\text { less experienced users. }\end{array}$ \\
\hline & H8 & $\begin{array}{l}\text { Lecturers influence behavioural intention to } \\
\text { use M-learning for male more positively for } \\
\text { experienced users of mobile devices than for } \\
\text { less experienced users. }\end{array}$ \\
\hline & H9 & $\begin{array}{l}\text { Personal innovativeness influences } \\
\text { behavioural intention to use M-learning more } \\
\text { positively for experienced users of mobile } \\
\text { devices than for less experienced users }\end{array}$ \\
\hline & H10 & $\begin{array}{l}\text { Self-management of learning influences } \\
\text { behavioural intention to use M-learning more } \\
\text { positively for experienced users of mobile } \\
\text { devices than for less experienced users. }\end{array}$ \\
\hline
\end{tabular}

\section{DISCUSSION}

This study focused primarily on identifying cultural and social factors that impact the acceptance of M-learning. The study model involved measuring ten assumptions using the moderators of gender and previous experience. Recognising the importance of moderators is also helpful for determining which factors influence M-learning in the target population (Saudi Arabian university students). Determining the impact of these moderators is helpful when seeking to identify the needs of the target population and their characteristics to deal with M-learning context. More detail on these aspects are provided in the section that follows.

\subsection{Moderator Variables}

Moderator variables are crucial components of the UTAUT framework that explain the impact of social, biological and/or cultural factors on M-learning acceptance. A number of the studies discussed earlier have demonstrated that gender, age and experience of using mobile technologies mediate learners' acceptance of M-learning. In particular, in [9] and [15] among others identified the significant role of age, experience and 
gender moderators in mediating the impact of selfmanagement of learning and effort expectancy on M-learning acceptance.

\subsubsection{Experience}

It has been established here that experience moderates performance expectancy, effort expectancy, lecturers' influence, personal innovativeness and self-management of learning in students' adoption of M-learning technologies. Specifically, it was found that performance expectancy and lecturers' influence are stronger predictors of M-learning adoption among students with three years or less of mobile experience than for students with more than three years of such experience. This finding is partially congruent with [15], who found a similar pattern for lecturers' influence. However, the present study found a higher $t$-value for performance expectancy for the "three years or less" group than that reported by [15] $(\mathrm{t}=6.48$ vs. $\mathrm{t}=2.82$, respectively). This difference suggests that the significance of prior experience of mobile devices for performance expectancy is higher in the present study.

Additionally, the present findings indicate that effort expectancy is a stronger predictor of M-learning adoption for students with longer experience with mobile technologies (7.680 vs. 7.205). This result, which is consistent with a number of studies, including [27] \& [30], seems counterintuitive and invites further research. Finally, it was found that self-management of learning is a stronger predictor of Mlearning use for students with longer experience of mobile technologies (6.260 vs. 5.434). This finding indicates that experience with mobile technologies may develop capacities of self-discipline and critical thinking that are crucial for mobile learning.

\subsubsection{Gender}

The study identified gender as a significant moderator of Mlearning acceptance among Saudi learners. Specifically, it was found that performance expectancy is a stronger predictor of M-learning adoption for male than for female respondents (6.853 vs. 4.231). At the same time, however, there is no tangible variation in the significance of effort expectancy for men and women. Similarly, it was found that the lecturers' influence has a comparable impact on both gender groups (5.514 vs. 5.708), which may imply that the role of social influence in educational context is moderate for both men and women. However, unlike [9], the present study employed a narrow definition of social influence as lecturers' influence. The inclusion of other sources of social influence, such as friends, family and colleagues, might have yielded different results.

As for the self-management of learning, the present study confirmed that this factor is a stronger predictor of M-learning usage for female than for male respondents. This finding is consistent with the findings of [9]. It should be noted, however, that the identification of a role for gender in acceptance of M-learning requires an elaborated interpretative framework that takes account of issues of gender socialization and gender roles in KSA. In particular, inter-gender differences may be explained by the differences in male and female social and educational practices, perceptions and roles. In particular, the effects of the gender moderator may be explained by gender segregation in KSA $n$ education and by differential access to education services for males and females. Similarly, sociological and psychological interpretation will be required to understand the impact of the experience variable on M-learning adoption among students.

\subsection{Main finding}

The present study advanced three research questions:

1. What factors affect M-learning acceptance among Saudi students?

2. How do gender and experience of mobile learners moderate acceptance of M-learning?

3. How can educators positively influence acceptance of Mlearning among Saudi students, given the role of various factors in technology acceptance?

The research findings confirm that performance expectancy, effort expectancy, lecturer's influence, self-management of learning and personal innovativeness are all major factors affecting learners' intention to use M-learning. All hypotheses are listed in Table 5 were supported and validated. In contrast to what was predicted, performance expectancy is seen to influence behavioral intention to use M-learning more positively for experienced users of mobile devices than for less experienced ones. The research has also highlighted thought-provoking variations in the predictive strength of Mlearning factors. Specifically, it was found that effort expectancy is the weakest predictor of learners' intention to use M-learning.

The study also shows that experience and gender are strong moderators of M-learning acceptance in KSA. Specifically, the key finding here is the stronger role for males in Saudi society of performance expectancy in adoption of M-learning. This finding may be explained by the greater openness of career opportunities and professional growth for males than for females in KSA.

Finally, based on these findings, a number of proposals can be advanced as to how educators can improve M-learning acceptance among learners:

- Pay attention to UX (user experience) and ease of use of M-learning courses and applications in order to limit the negative impact of effort expectancy;

- Tailor M-learning courses and functionality to students' capacities for self-management of learning and personal innovativeness;

- Leverage the impact of lecturers' influence in attracting students to M-learning courses;

- Identify gender-specific patterns of M-learning course usage in order to customize course options;

- Pay attention to user experience of mobile devices in Mlearning course development and implementation.

\section{RECOMMENDATION}

The study has many findings that can be turned into recommendations. In particular, this study has produced two main groups of suggestions. First, suggestions in the Mlearning field within universities and educational institutes, and second, suggestions related to target audiences who are interested in using M-learning.

As mentioned previously, educational institutions in KSA seek to invest in technologies for teaching and learning. One of these new technological tools is M-learning. The main purpose of these technological investments is to provide multiple choices in the educational process and to take advantage of smart devices using the Internet in general and M-learning in particular. In taking advantage of this trend, it is possible to facilitate cooperation between the government and commercial sectors to better promote the spread of M-learning through various means. This may include offering online courses that use features of M-learning and presenting 
applications that work in the M-learning field. Furthermore, it is useful to take advantage of mobile technologies to better design and implement educational applications. These technologies can help universities' students to acquire knowledge through reliable and associated with informatics that meet their needs. The results of this study may help to provide students with educational opportunities, particularly those who find it difficult to obtain a formal education (on campus) and who are searching for opportunities to complete higher levels of education. In some cases, those higher levels of education are not otherwise available within learning institutes in KSA. However, this higher education is necessary to improve students' abilities and to ultimately enhance their communities. This study demonstrates that M-learning can become an effective way of increasing the level of education available in Saudi Arabian society. This increase in education could represent a good investment in the country's future. $\mathrm{KSA}$ is also in a position to benefit from other countries' experiences so that they may better develop an infrastructure for online learning.

The target audiences for distance learning may have difficulty learning in other contexts. In the case of female students, they face limitations because of the cultural heritage of Saudi Arabian society and the need to segregate the genders. Saudi Arabian women's education is influenced by gender segregation for all levels of education. Within the female system, academic disciplines are not especially diverse, and there is an inadequate number of trained staff in many female sectors of Saudi Arabian universities. Both sides dramatically influence the level of sophistication in women society. Mlearning could be helpful to address these obstacles and the gaps between the systems by integrated academic programs that can be implemented through M-learning. Furthermore, the results concerning cultural moderators indicate that male and female populations are keenly interested in using $\mathrm{M}$ learning. They are open to both official learning channels within university programs and websites and unofficial learning channels for personal learning through blogs and forums in various disciplines. It is therefore important for valid, reliable educational materials to be provided to take full advantage of the benefits of M-learning. Also, presenting trust certificates for M-learning applications in one of the applications' screens could increase students' levels of confidence to use M-learning applications widespread. Providing numerous academic and educational materials would meet the target population's growing desire to learn. It would also provide students with efficient forms of online learning in universities and other academic institutions.

\section{CONCLUSION}

This study focuses on identifying the factors that increase students' acceptance levels of M-learning in higher education institutions in KSA. The study has sought to reduce the existing gaps between a religiously conservative Saudi Arabian culture and the requirements of public life. The overall aim is to enable both genders to complete whatever levels of education they desire in whichever disciplines they choose.

This study has indicated that M-learning is influenced by many cultural factors. For example, M-learning is impacted by women's desire to learn through multiple channels, to be appropriate with her nature, and the societal requirement of gender segregation that is enforced by governmental policy. This study seeks to identify the link between the acceptance of technology-based educational systems and the Islamic culture of Saudi Arabian communities. The results show that there is a positive relationship between the two cultural moderators used in this study's theoretical framework. This has led the study population to accept M-learning in higher education institutions in KSA. These findings support the continued creation of M-learning applications, as they are well aligned with the existing culture and have the potential to address existing educational needs.

This study has several limitations that can be addressed by future studies. For example, it would be possible to test and validate the theoretical framework of this study using additional multicultural Arabic societies, which would help to validate this study model on a larger scale. Furthermore, it is important to test the cultural moderators that were used in this study. Greater expansion may help to identify the target populations' characteristics and to facilitate the spread of the M-learning approach in a short timeframe. Future studies that focus on the acceptance of M-learning represent a bold trend that has already been adopted by various educational institutions, both locally and globally. This study has significantly enabled the spread of the M-learning approach in the present and even into the future as it provides an appropriate means of facilitating M-learning.

\section{REFERENCES}

[1] Behera, S. K. (2013). E-and M-Learning: A comparative study. International Journal on New Trends in Education and Their Implications, 4(3), 65-78.

[2] Chen, H.-R., \& Huang, H.-L. (2010). User Acceptance of Mobile Knowledge Management Learning System: Design and Analysis. Educational Technology \& Society, 13 (3), 70-77.

[3] Kukulska-Hulme, A., \& Traxler, J. (Eds.). (2005). Mobile learning: A handbook for educators and trainers. Psychology Press.

[4] Al-Fahad, F. N. (2009). Students' Attitudes and Perceptions towards the Effectiveness of Mobile Learning in King Saud University, Saudi Arabia. Online Submission, 8(2).

[5] Jaradat, R. M. (2014). Students' Attitudes and Perceptions towards using m-learning for French Language Learning: A case study on Princess Nora University. Int. J. Learn. Man. Sys, 2(1), 33-44.

[6] MacCallum, K., \& Jeffrey, L. (2009). Identifying discriminating variables that determine mobile learning adoption by educators: An initial study. Same places, different spaces. Proceedings ascilite Auckland 2009, 602-608.

[7] Goh, T., \& Kinshuk, D. (2006). Getting ready for mobile learning - adaptation perspective. Journal of Educational Multimedia and Hypermedia, 15(2), 175-198.

[8] Milrad, M., Hoppe, U., Gottdenker, J., \& Jansen, M. (2004). Exploring the use of mobile devices to facilitate educational interoperability around digitally enhanced experiments. In Wireless and Mobile Technologies in Education, 2004. Proceedings. The 2nd IEEE International Workshop on (pp. 182-186). IEEE.

[9] Wang, Y. S., Wu, M. C., \& Wang, H. Y. (2009). Investigating the determinants and age and gender differences in the acceptance of mobile learning. British Journal of Educational Technology, 40(1), 92-118. 
[10] Garg, V. (2013, January 15). The Emergence Of Mobile Learning For Higher Education In Kingdom Of Saudi Arabia. Retrieved December 2015 from http://www.upsidelearning.com/blog/index.php/2013/01/ 15/emergence-of-mobile-learning-for-higher-educationin-kingdom-of-saudiarabia/Documents/PR_REP_009A.pdf

[11] Aitnews. (2013, August 27). UAE and Saudi Arabia of the most commonly used of smartphones in the world. Arab Portal Technical News. Retrieved November 13, 2014, http://www.aitnews.com/latest-it-news/technologyresearch-and-studies-news/119939.html

[12] CITC. (2013). IT Report 2013. Retrieved November 13, 2014

http://www.citc.gov.sa/arabic/MediaCenter/Annualreport

[13] InfoDev. (2010). ICT in school education (primary and secondary). Retrieved Jan, 10, 2012, from p://www.infodev.org/en/Document.1016.pdf

[14] Kennedy, G., Dalgarno, B., Bennett, S., Judd, T., Gray, K., \& Chang, R. (2008). Immigrants and natives: Investigating differences between staff and students' use of technology. Hello! Where are you in the landscape of educational technology? Proceedings ascilite Melbourne 2008, 484-492.

[15] Abu-Al-Aish, A. and Love, S. 2013. Factors influencing students' acceptance of M-Learning: an investigation in higher education. The International Review of Research in Open and Distributed Learning, 14(5), 82-107.

[16] Nassuora, A. B. (2012). Students acceptance of mobile learning for higher education in Saudi Arabia. American Academic \& Scholarly Research Journal,4(2), 24-30.

[17] Chong, J. L., Chong, A. Y. L., Ooi, K. B., \& Lin, B. (2011). An empirical analysis of the adoption of $\mathrm{m}$ learning in Malaysia. International Journal of Mobile Communications, 9(1), 1-18.

[18] Motiwalla, L. F. (2007). Mobile learning: A framework and evaluation.Computers \& Education, 49(3), 581-596.

[19] Crawford, V. M. (2007). Creating a Powerful Learning Environment with Networked Mobile Learning Devices. Educational Technology, 47(3), 47-50

[20] Brown, R., Ryu, H., \& Parsons, D. (2006, November). Mobile helper for university students: a design for a mobile learning environment. In Proceedings of the 18th Australia conference on Computer-Human Interaction: Design: Activities, Artefacts and Environments (pp. 297300). ACM.

[21] Chao, P. Y., \& Chen, G. D. (2009). Augmenting paperbased learning with mobile phones. Interacting with Computers, 21(3), 173-185.

[22] Liu, Z., Zhao, G., Zheng, W., \& Jin, J. (2008). The research and exploration of mobile-learning based on $W e b$ 2. 0. Paper presented at the International Symposium on Knowledge Acquisition and Modeling (KAM'08), Wuhan, China

[23] Phuangthong, D., \& Malisawan, S. (2005, August). A study of behavioral intention for $3 \mathrm{G}$ mobile Internet technology: Preliminary research on mobile learning. In Proceedings of the Second International Conference on eLearning for Knowledge-Based Society (pp. 4-7)
[24] Altameem, T. (2011). Contextual mobile learning system for Saudi Arabian universities. International Journal of Computer Applications, 21(4), 21.

[25] Vision 2030. (2016). National Transformation Program. Retrieved August 11, 2016, http://vision2030.gov.sa/en/ntp

[26] Adkins, S. (2011). The US Market for Mobile Learning Products and Services: 2010-2015 Forecast and Analysis Retrieved Jan, 10, 2012, from http://www.ambientinsight.com/Resources/Documents/A mbient-Insight-2010-2015-US-Mobile-Learning-MarketExecutive-Overview.pdf

[27] Venkatesh, V., Morris, M. G., Davis, G. B., \& Davis, F D. (2003). User acceptance of information technology: Toward a unified view. MIS Quarterly, 27(3), 425-478.

[28] Ju, T. L., Sriprapaipong, W., \& Minh, D. N. (2007). On the success factors of mobile learning. Proceeding for the 5th International Conference on ICT and Higher Education. Bangkok, Thailand. Retrieved from http://phd- e\%20Learning.pdf it.siam.edu/Conference2007/documents/On\%20the\%20S uccess $\% 20$ Factors $\% 20$ of\%20Mobile\%20Learning.pdf

[29] Iqbal, S., \& Qureshi, I. A. (2012). M-learning adoption: A perspective from a developing country. The International Review of Research in Open and Distance Learning, 3(3), 147-164.

[30] Lowenthal, J. (2010). Using mobile learning: determinates impacting behavioral intention. The American Journal of Distance Education, 24(4), 195206.

[31] Jairak, K., Praneetpolgrang, P., \& Mekhabunchakij, K. (2009). An acceptance of mobile learning for higher education students in Thailand. Proceeding for the 6th International Conference on E-Learning from Knowledge - Based Society, 17-18 December 2009, Thailand, 36.1-36-8.

[32] Yusuf, N. (2013) The future of global education, International Journal of Business and Economic Development, 1(3), 75-82.

[33] Chanchary, F.H. and Islam, S. (2011). Mobile learning in Saudi Arabia: prospects and challenges. 5th international conference on e-learning, 1-6.

[34] Al-Barhamtoshy, H.M. and Himdi, T. (2013). Designing and Implementing M-Learning Model, 1-13.

[35] Razek, M.A. and Bardesi, H. J. (2011) Towards adaptive mobile learning system. IEEE, 11th International Conference on Hybrid Intelligent Systems (HIS), 493498.

[36] Creswell, J. W. (2008). Educational Research: Planning, Conducting, and Evaluating Quantitative and Qualitative Research: Pearson/Merrill Prentice Hall.

[37] Sekaran, U. (2003). Research methods for business: a skill building approach. Journal of Education for Business, 68(5), 316-317.

[38] Wuensch, K. (2005). What is a Likert Scale? and How Do You Pronounce 'Likert?. East Carolina University. Retrieved 22 November 2015 from http://core.ecu.edu/psyc/ wuenschk/StatHelp/Likert.htm. 
[39] Fornell, C., \& Larcker, D. F. (1981). Evaluating structural equation models with unobservable variables and measurement error. Journal of marketing research, $39-50$.

[40] Bagozzi, R. P., \& Yi, Y. (1988). On the evaluation of structural equation models. Journal of the academy of marketing science, 16(1), 74-94.

[41] Hair, J. F., Black, W., Babin, B., \& Anderson, R. (2010). Multivariate data analysis: a global perspective (7th ed.). New Jersey: Pearson.

[42] Straub, D., Limayem, M., \& Karahanna-Evaristo, E. (1995). Measuring system usage: Implications for IS theory testing. Management science, 41(8), 1328-1342.

\section{APPENDIX}

\begin{tabular}{|c|c|c|}
\hline \multicolumn{3}{|c|}{$\begin{array}{l}\text { Appendix A: Frequencies of Demographic } \\
\text { questions ( } N=401)\end{array}$} \\
\hline Category of Participants & No. & $\%$ \\
\hline \multicolumn{3}{|l|}{ Q1. Gender } \\
\hline Male & 194 & 48.4 \\
\hline Female & 207 & 51.6 \\
\hline \multicolumn{3}{|l|}{ Q2. Age Group } \\
\hline 18 Years or Less & 8 & 2.0 \\
\hline $19-20$ & 77 & 19.2 \\
\hline 21- 22 & 58 & 14.5 \\
\hline $23-24$ & 35 & 8.7 \\
\hline $25-26$ & 27 & 6.7 \\
\hline 27 Years or Upper & 196 & 48.9 \\
\hline \multicolumn{3}{|c|}{ Q3. Level of education } \\
\hline Undergraduate & 65 & 16.2 \\
\hline Graduate & 251 & 62.6 \\
\hline Postgraduate & 85 & 21.2 \\
\hline \multicolumn{3}{|c|}{ Q4. Experience of Smart mobile phone } \\
\hline Less than 1 year & 11 & 2.7 \\
\hline 1-2 Years & 37 & 9.2 \\
\hline 3-4 Years & 148 & 36.9 \\
\hline 5 years or more & 205 & 51.1 \\
\hline \multicolumn{3}{|c|}{ Q5. e-learning knowledge level } \\
\hline Moderate & 138 & 34.4 \\
\hline Good & 106 & 26.4 \\
\hline Very Good & 157 & 39.2 \\
\hline \multicolumn{3}{|c|}{ Q6. Frequently using m-service for learning } \\
\hline 1 time per week & 150 & 37.4 \\
\hline
\end{tabular}

\begin{tabular}{|lcc|}
\hline 1-5 times per day & 100 & 24.9 \\
\hline 5-10 times per day & 100 & 24.9 \\
\hline More than 10 & 51 & 12.7 \\
\hline Q7. Internet plan & & \\
\hline Prepaid & 208 & 51.9 \\
\hline Post-paid & 144 & 35.9 \\
\hline Both & 49 & 12.2 \\
\hline
\end{tabular}

Q8. Type of ISP (internet Service Providers)

3G or 4G $\quad 90 \quad 22.4$

$\begin{array}{lll}\text { Both } & 189 & 47.1\end{array}$

Q9. Mobile OS usage

\begin{tabular}{lcc} 
Apple IOS & 131 & 32.7 \\
\hline Android & 171 & 42.6 \\
\hline Windows & 10 & 2.5 \\
BlackBerry & 3 & .7 \\
\hline Apple \& Android & 34 & 8.5 \\
\hline Android \& Windows & 25 & 6.2 \\
\hline Apple \& Windows & 14 & 3.5 \\
\hline Apple \& Android \& Windows & 13 & 3.2 \\
Q10. Kind of smartphone is used & \\
\hline Smart Phone & 226 & 56.4 \\
\hline Tablet & 10 & 2.5 \\
\hline iPad & 13 & 3.2 \\
\hline Smart Phone \& Tablet & 48 & 12.0 \\
\hline Smart Phone \& iPad & 83 & 20.7 \\
\hline Smart Phone \& Tablet \& iPad & 17 & 4.2 \\
\hline PDA/Palmtop & 1 & .2 \\
\hline Smart Phone \& iPad \& & 3 & .7 \\
PDA/Palmtop & & \\
\hline
\end{tabular}

Q11. Prefer Device for using in $\mathrm{m}$ learning

\begin{tabular}{lcc} 
Smart Phone & 119 & 29.7 \\
Tablet & 51 & 12.7 \\
iPad & 86 & 21.4 \\
Palmtop & 8 & 2.0 \\
Smart Phone \& iPad & 60 & 15.0 \\
\hline Tablet \& iPad & 16 & 4.0 \\
Smart Phone \& Tablet & 27 & 6.7 \\
Smart Phone \& Tablet \& iPad & 34 & 8.5 \\
\hline
\end{tabular}

